\title{
M3MS-19IN0101201
}

\section{Modeling Intra-granular}

Fission Gas Bubble

Evolution in Uranium

Dioxide during Transients

Milestone Report

G. Pastore

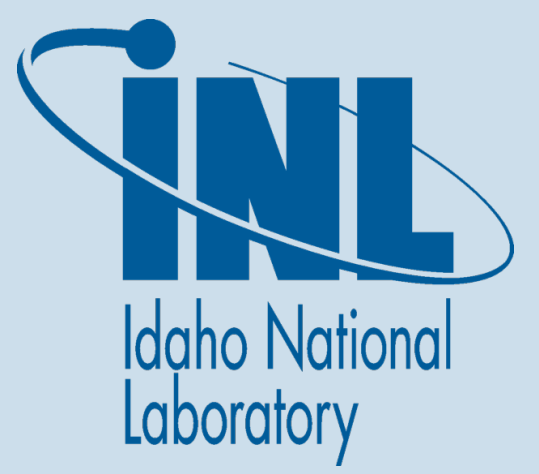

Fission Gas SciDAC 2

Simulation of Fission Gas in Uranium Oxide Nuclear Fuel 


\section{NOTICE}

This information was prepared as an account of work sponsored by an agency of the U.S. Government. Neither the U.S. Government nor any agency thereof, nor any of their employees, makes any warranty, express or implied, or assumes any legal liability or responsibility for any third party's use, or the results of such use, of any information, apparatus, product, or process disclosed herein, or represents that its use by such third party would not infringe privately owned rights. The views expressed herein are not necessarily those of the U.S. Nuclear Regulatory Commission. 
INL/EXT-19-56019

\title{
M3MS-19IN0101201
}

\section{Modeling Intra-granular Fission Gas Bubble Evolution in Uranium Dioxide during Transients}

\author{
Milestone Report
}

G. Pastore

September 2019

Idaho National Laboratory

Fuel Modeling and Simulation Department Idaho Falls, ID 83415

\author{
Prepared for the \\ U.S. Department of Energy \\ Office of Nuclear Energy \\ Under U.S. Department of Energy-Idaho Operations Office \\ Contract DE-AC07-99ID13727
}




\begin{abstract}
The SciDAC milestone M3MS-19IN0101201 on Modeling Intra-granular Fission Gas Bubble Evolution in Uranium Dioxide during Transients was completed with the development, testing and implementation in the Bison code of an engineering model for intra-granular fission gas bubble evolution that is applicable to transient conditions. The model extends the previous work on modeling bubble evolution during normal operating conditions to include additional complexity that arises during transient situations, in particular, the so-called intra-granular bubble coarsening. This phenomenon refers to the appearance of a second population of coarsened bubbles with diameters of tens to hundreds of $\mathrm{nm}$, which co-exist with nanometric bubbles present also during normal operating conditions and are responsible for a large portion of transient fuel swelling. The developed model considers growth of bubbles along dislocations, associated with the absorption of vacancies available in the dislocation core region, and favored by pipe diffusion of fission gas atoms. The model also utilizes the formulation for the gas atom resolution rate developed in the present SciDAC project through molecular dynamics simulations by other institutions. The present work therefore demonstrates an operational multiscale approach, based on collaboration within the project. The model is validated to an extensive experimental dataset of ramp tested uranium dioxide fuel samples. Additionally, we present new applications of the base model for bubble evolution during normal operating conditions to Bison engineering simulations of $\mathrm{Cr}_{2} \mathrm{O}_{3}$-doped fuel rods irradiated in the Halden reactor. Simulation results in terms of integral fission gas release in the fuel rods are compared to the available experimental data, pointing out significant improvements in the engineering predictions compared to application of the empirical model that was available in Bison before the SciDAC developments.
\end{abstract}




\section{Contents}

\begin{tabular}{ll}
\hline Introduction & 1
\end{tabular}

$1 \quad$ Model development for intra-granular bubble evolution during transients 2

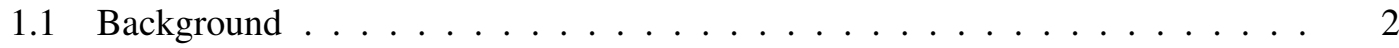

1.2 Modeling of fundamental mechanisms and multiscale coupling . . . . . . . . 3

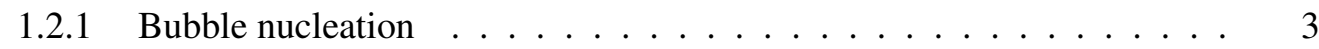

1.2.2 $\quad$ Resolution and multiscale coupling to atomistic calculations . . . . . . 3

1.2 .3 Gas atom trapping $\ldots \ldots \ldots \ldots \ldots \ldots$

1.2.4 Vacancy absorption . . . . . . . . . . . . . . . . . 5

1.2 .5 Bubble coalescence . . . . . . . . . . . . . . . . . 6

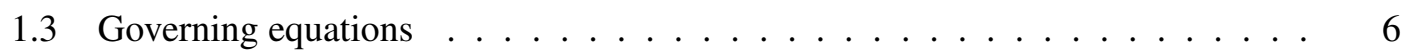

1.4 Initial experimental validation $\ldots \ldots \ldots \ldots \ldots \ldots$

$1.4 .1 \quad$ Experimental database $\ldots \ldots \ldots \ldots \ldots$

1.4 .2 Results $\ldots \ldots \ldots \ldots \ldots \ldots$

1.4 .3 Impact of multiscale coupling for resolution . . . . . . . . . . . 11

2 Application of SciDAC model to Halden fuel rod simulations using Bison 13

2.1 Description of Halden test IFA-677.1 . . . . . . . . . . . . . . . . . . . . . 13

2.2 Bison simulation results $\ldots \ldots \ldots \ldots \ldots \ldots$

\begin{tabular}{lr}
\hline Conclusions & 17
\end{tabular}

\begin{tabular}{ll}
\hline Acknowledgments & 18
\end{tabular}

\begin{tabular}{lr}
\hline References & 19
\end{tabular} 


\section{Introduction}

The accurate description of intra-granular fission gas behavior during both normal operating and transient conditions is a fundamental part of fission gas behavior models applied in fuel performance codes. The relevant physical phenomena include diffusion of gas atoms towards grain boundaries coupled to the evolution of intra-granular bubbles. Bubbles nucleate in fuel grains due to the low solubility of the fission gases and evolve through trapping of dissolved gas atoms and the counteracting process of irradiation-induced gas atom resolution [1-5]. Intragranular bubbles not only affect the gas diffusion rate to grain boundaries but also contribute to fuel swelling, although intra-granular gaseous swelling becomes significant compared to grainboundary swelling only at high burnup or during transients [6-8].

Within the SciDAC project on Simulation of Fission Gas in Uranium Oxide Nuclear Fuel, the engineering-scale development effort at INL aims to develop improved models for intra-granular fission gas behavior to be applied in fuel performance codes such as Bison. In previous years, we developed a reduced parameter model for the evolution of intra-granular fission gas behavior during normal operating reactor conditions. The model utilizes a single-size cluster dynamics approach to track the evolution of nanometric intra-granular bubbles, and is currently available in the Bison code. Details of these developments are given in the FY-18 INL milestone report [9] and in publications related to this work [10-12].

During FY-19, an extended fission gas bubble evolution model was developed in order to consider transient evolution in addition to behavior during normal operating conditions. In particular, a new modeling capability was developed to account for the so-called intra-granular bubble coarsening [6-8 $-13,-16]$ and the associated large fuel swelling during transients. The engineering model utilizes molecular dynamics (MD) calculations for gas atom resolution performed in the present SciDAC project by Setyawan et al. [17], demonstrating an operational multiscale approach. Furthermore, validation to experimental data for transient-tested fuel was performed.

In addition to this, during FY-19 the original normal operation model was applied to new Bison engineering simulations of $\mathrm{Cr}_{2} \mathrm{O}_{3}$-doped fuel rod experiments in the Halden reactor. Simulation results for fission gas release were compared to experimental data and to previous fission gas models in Bison, providing additional demonstration and validation of the SciDAC developments to engineering fuel rod simulations.

Completion of the SciDAC milestone M3MS-19IN0101201 through the above developments is described in this report. Chapter 1 deals with the model for bubble evolution during transients, including theoretical basis, main equations, initial validation, and the multiscale coupling to MD calculations for resolution. Chapter 2 gives an account of the recent application of the SciDAC developments at the engineering scale to Bison simulations of Halden fuel rod experiments. 


\section{Model development for intra-granular bubble evolution during transients}

\subsection{Background}

During normal operating conditions, intra-granular fission gas bubbles generally have diameters of one to a few nanometers. However, experiments have shown that during transient conditions such as power ramps, a strongly bi-modal bubble size distribution develops, with the appearance of a second population of coarsened bubbles with diameters of tens to hundreds of nm [6]-8 13[16]. Bubble coarsening during transients is associated with large local gaseous swelling of up to $7-8 \%$ volumetric fraction [6]8|13] and is therefore of high engineering importance. Recent research at INL within this SciDAC project has led to the development of a bubble coarsening theory that invokes the role of dislocations as a source of vacancies and preferential bubble growth along dislocations.

An alternative explanation for the development of a bi-modal bubble size distribution invokes the role of resolution. In particular, as resolution becomes less effective with increasing bubble radius, it has been postulated that a fraction of the bubbles may surmount a 'critical' size beyond which they are able to further grow without significant restriction, e.g., [18]. This mechanism provides an explanation for bubble coarsening that is alternative, or complementary, to the role of dislocations, and may be further investigated in the future.

On the other hand, the bubble coarsening theory applied in the present work finds support in the experimental observations showing coarsened bubbles associated with dislocations (e.g., [8, [19). It also appears to be a straightforward conceptual extension to dislocation defects of the established behavior at grain boundary defects. The role of dislocations in bubble coarsening has been considered in earlier modeling efforts on intra-granular bubble growth during postirradiation annealing [13].

The newly developed transient model extends the normal operating conditions model developed in previous years by adding the evolution of a second population of bubbles along dislocations, which is subject to coarsening. The coarsening mechanism is naturally activated during transient conditions according to the physical representation in the model. While both small bubbles in the bulk and coarsening bubbles at dislocations are modeled, only the average size of each population is considered. In this sense, the new model can be considered as a 'two-size' description of intra-granular bubble evolution. In the following, we provide a summary of the model and present initial validation results. 


\subsection{Modeling of fundamental mechanisms and multiscale coupling}

The in-pile evolution of intra-granular bubbles in oxide nuclear fuel is governed by the fundamental mechanisms of bubble nucleation, irradiaton-induced resolution of gas atoms from the bubbles back into the lattice, gas atom trapping and vacancy absorption at bubbles, and bubble coalescence. Modeling of these mechanisms in the current enginering-scale model is described in the following. Multiscale coupling to atomistic calculations from Setyawan et al. [17], in particular, is dealt with in Section 1.2.2.

\subsubsection{Bubble nucleation}

Two different approaches have been proposed to model the rate of fission gas bubble nucleation in $\mathrm{UO}_{2}$. The homogeneous mechanism describes bubble nucleation as a consequence of diffusion-limited precipitation of gas atom dimers [3|20|21], while the heterogeneous mechanism considers nucleation as a direct consequence of fission spikes [10|22[23]. Although both mechanisms are presumably active, following our previous work [10] we model the nucleation of small intra-granular bubbles in the bulk of the grain as heterogeneous. The nucleation rate $v\left(\mathrm{~m}^{-3} \mathrm{~s}^{-1}\right)$ is calculated as

$$
\mathrm{v}=2 \eta \dot{F}
$$

where $\eta$ (bubbles per fission fragment) is in the range 5-25 [19|22], $\dot{F}$ (fissions $\mathrm{m}^{-3} \mathrm{~s}^{-1}$ ) is the fission rate density, and the factor of 2 corresponds to the approximate number of fragments generated by each fission event.

Considering a simplified approach, the nucleation rate of bubbles along dislocations $v_{d}\left(\mathrm{~m}^{-3} \mathrm{~s}^{-1}\right)$ is modeled as follows

$$
v_{d}=K \cdot \frac{\mathrm{d} \rho_{d}}{\mathrm{~d} t}
$$

where $\rho_{d}\left(\mathrm{~m}^{-2}\right)$ is the space-averaged dislocation density and $K\left(\mathrm{~m}^{-1}\right)$ is a parameter representing the number of bubbles nucleated per dislocation. Note that in this preliminary approach, we consider a nonzero initial number of nucleated bubbles at dislocations.

\subsubsection{Resolution and multiscale coupling to atomistic calculations}

For consideration of irradiation-induced resolution of gas atoms from bubbles in this work, following the conclusions of Govers et al. [24] and Setyawan et al. [17], we assume that resolution is induce by the thermal spike due to electronic stopping (heterogeneous mechanism). For the resolution rate, we adopt the following expression developed through molecular dynamics calculations from Setyawan et al. [17]: 


$$
\alpha=\left(a \exp \left(-b_{1} \cdot R\right)+\frac{b_{0}-a}{1+c \cdot R^{2}} \exp \left(-d \cdot R^{2}\right)\right) \cdot \dot{F}
$$

where $\alpha\left(\mathrm{s}^{-1}\right)$ is the resolution rate, $R(\mathrm{~m})$ is the bubble radius and $a, b_{0}, b_{1}, c, d$ are parameters from [17]. In particular, we considered the parameters corresponding to a ratio between the thermal spike energy and the total electronic stopping power of 0.73 , as suggested in [17]. This formulation for the re-solution rate improves and extends through atomistic methods the legacy work on resolution from Turnbull [22], and introduces consideration of the thermal spike energy dissipation, the off-centered ballistic distance (i.e., the distance between the thermal spike and the bubble center), and the reduced efficiency of resolution with increasing bubble radius. The latter aspect is particularly important for the present work, where large coarsened bubbles are considered. The reduced resolution efficiency with increasing bubble radius evaluated by Setyawan and co-workers through lower-length scale modeling confirms the theoretical conclusions from other authors, e.g., [16]18|25].

\subsubsection{Gas atom trapping}

In this work, we consider the trapping of gas atoms at (spherical) intra-granular bubbles as well as at dislocations. Following Ham [26], the trapping rate at bubbles is calculated as

$$
\beta=4 \pi D R N
$$

where $\beta\left(\mathrm{s}^{-1}\right)$ is the trapping rates, $D\left(\mathrm{~m}^{2} \mathrm{~s}^{-1}\right)$ the single gas atom diffusion coefficient, and $N\left(\mathrm{~m}^{-3}\right)$ the bubble number density. For the trapping rate at dislocations, we write

$$
\beta^{\prime}=\frac{2 \pi D \rho_{d}}{\ln \frac{r_{w s, d}}{r_{d}}-\frac{3}{5}}
$$

where $\beta^{\prime}\left(\mathrm{s}^{-1}\right)$ is the trapping rate, $r_{w s, d}=1 / \sqrt{\pi \rho_{d}}(\mathrm{~m})$ the radius of the Wigner-Seitz cell associated with a dislocation, and $r_{d}(\mathrm{~m})$ is the dislocation core radius, taken equal to five times the magnitude of the $\mathrm{UO}_{2}$ Burgers vector. As a modelling assumption, gas atoms captured by dislocations are considered as instantaneously trapped into dislocation bubbles. The hypothesis is justified by the rapid diffusion of species near the core of dislocations (pipe diffusion), as shown, e.g., by Murphy et al. [27]. 


\subsubsection{Vacancy absorption}

We assume that bubbles at dislocations may absorb vacancies when their internal energy (pressure) exceeds the mechanical equilibrium pressure. This condition is naturally triggered during transients to high temperatures. Considering spherical bubbles, and following [28--30], we compute the absorption rate of vacancies at a bubble, $n_{v}(/)$, as

$$
\frac{\mathrm{d} n_{v}}{\mathrm{~d} t}=\frac{2 \pi D_{v} \delta}{k T \zeta}\left(p-p_{e q}\right)
$$

where $D_{v}\left(\mathrm{~m}^{2} \mathrm{~s}^{-1}\right)$ is the vacancy diffusion coefficient along dislocations, $\delta(\mathrm{m})$ the radius of the equivalent Wigner-Seitz cell associated with a dislocation bubble, $k\left(\mathrm{~J} \mathrm{~K}^{-1}\right)$ the Boltzmann constant, $T(\mathrm{~K})$ the local temperature, $p$ and $p_{e q}(\mathrm{~Pa})$ are the bubble pressure and the equilibrium pressure, respectively, and $\zeta(/)$ is a dimensionless factor. The radius of the Wigner-Seitz cell is determined by the relationship $4 / 3 \pi N_{d} \delta^{3}=1$, where $N_{d}\left(\mathrm{~m}^{-3}\right)$ is the number density of bubbles at dislocations. The dimensionless factor is calculated as [30]

$$
\zeta=\frac{10 \psi\left(1+\psi^{3}\right)}{-\psi^{6}+5 \psi^{2}-9 \psi+5}
$$

where $\psi=R_{d} / \delta$ is the ratio between the radii of the dislocation bubble and of the cell. Considering the van der Waals equation of state (neglecting the pressure correction, e.g., [1]), the pressure of the gas in the bubble is

$$
p=\frac{k T}{\Omega} \eta
$$

where $\Omega\left(\mathrm{m}^{3}\right)$ is the vacancy volume, $\eta(/)$ is the ratio between the number of atoms in dislocation bubbles, $n_{d}(-)$, and the number of vacancies in dislocation bubbles, $n_{v}$. The equilibrium pressure is determined by the surface energy, $\gamma\left(\mathrm{J} \mathrm{m}^{-2}\right)$, and the hydrostatic stress in the surrounding medium, $\sigma_{h}(\mathrm{~Pa})$, i.e.,

$$
p_{e q}=\frac{2 \gamma}{R_{d}}-\sigma_{h}
$$

As for the vacancy diffusion coefficient along dislocations, in the absence of data, we apply the assumption of the ratio between the vacancy diffusion coefficients at dislocations and in the bulk being the same as for interstitial Xe atoms. For this purpose, we consider previous work on bulk diffusivity of defects in $\mathrm{UO}_{2}$ [31] and on pipe diffusion of interstitials along dislocations [32] to derive the following tentative correlation for $D_{v}\left(\mathrm{~m}^{2} \mathrm{~s}^{-1}\right)$

$$
D_{v}(T)=3.8 \cdot 10^{-2} \exp \left(\frac{-1.84 \mathrm{eV}}{k T}\right)
$$




\subsubsection{Bubble coalescence}

As the radius of coarsened bubbles at dislocations can become comparable with the average inter-bubble distance, mechanical interaction between bubbles and the associated bubble coalescence need to be considered. Following [33], we consider intra-granular bubbles as a threedimensional system of spheres, randomly distributed according to a Poisson distribution. We neglect coalescence between nanometric bulk bubbles, and account for coalescence between (i) two large bubbles along dislocations and (ii) one dislocation bubble and one bulk bubble. The inter-connection between two large dislocation bubbles is modelled assuming that only pair interactions take place and considering bubbles as hard-spheres. In its final form, the equation for the variation rate of the bubble number density due to coalescence reads

$$
\frac{d N_{d}}{d V_{d}}=-4 \lambda N_{d}^{2}
$$

where $N_{d}\left(\mathrm{~m}^{-3}\right)$ is the number density of bubbles along dislocations, $V_{d}(\mathrm{~m})$ the bubble volume, and $\lambda=(2-\xi) /\left[2(1-\xi)^{3}\right]$ is a correction factor accounting for the hard-sphere assumption, with $\xi=\frac{4}{3} \pi R_{d}^{3} N_{d}$ being the porosity associated with dislocation bubbles. It is noted that the current formulation of the coalescence model may need further investigations to estimate the impact of the array disposition of bubbles along dislocations, which may increase the probability of interaction [34].

For modeling the interaction between a dislocation bubble and a bulk bubble, we assume that all of the bulk bubbles within a sphere of volume $V_{d}^{*}=\frac{4}{3} \pi\left(R_{d}+R\right)^{3}$ are captured by the expanding dislocation bubble, and transfer their gas content to the latter. The probability that a small bubble is incorporated by a growing dislocation bubble is $N \cdot d V_{d}^{*}$, with $d V_{d}^{*}=4 \pi\left(R_{d}+R\right)^{2} d R_{d}$. Consequently, the decrease in number density of small bulk bubbles is given by

$$
\frac{d N}{d V_{d}}=-N_{d} \cdot N
$$

\subsection{Governing equations}

Considering the mechanisms described in Section 1.2, the newly developed transient model of intra-granular bubble evolution extends the normal operating conditions model developed previously [9] by adding consideration of a second population of bubbles along dislocations, which is subject to coarsening driven by vacancy absorption. The coarsening mechanism is naturally activated during transient conditions according to the physical representation in the model. While both small bubbles in the bulk and coarsening bubbles at dislocations are modeled, only the average size of each population is considered.

The governing equations in the model's final form are: 


$$
\left\{\begin{array}{l}
\frac{\partial c}{\partial t}=D \nabla^{2} c-\left(\beta_{n}+\beta_{n_{d}}+\beta^{\prime}\right) c+\alpha_{n} m+\alpha_{n_{d}} m_{d}-2\left(v+v_{d}\right)+y \dot{F} \\
\frac{\partial m}{\partial t}=2 v+\beta_{n} c-\alpha_{n} m \\
\frac{\partial m_{d}}{\partial t}=2 v_{d}+\left(\beta_{n_{d}}+\beta^{\prime}\right) c-\alpha_{n_{d}} m_{d}
\end{array}\right.
$$

where $c\left(\mathrm{~m}^{-3}\right)$ is the concentration of single gas atoms, $m\left(\mathrm{~m}^{-3}\right)$ the concentration of gas atoms in bulk bubbles, $m_{d}\left(\mathrm{~m}^{-3}\right)$ the concentration of gas atoms in dislocation bubbles, and $y$ (atoms fission $^{-1}$ ) the fission yield of gas atoms. The other quantities are defined in Section 1.2. The number densities of bulk and dislocation bubbles evolve according to

$$
\begin{aligned}
& \frac{\partial N}{\partial t}=v-\alpha_{n} N \\
& \frac{\partial N_{d}}{\partial t}=v_{d}-\alpha_{n_{d}} N_{d}
\end{aligned}
$$

respectively. Additionally, variation of the number densities owing to coalescence is modeled as discussed in Section 1.2.5. The average number of gas atoms per bulk and dislocation bubble are

$$
\begin{aligned}
& n=\frac{m}{N} \\
& n_{d}=\frac{m_{d}}{N_{d}}
\end{aligned}
$$

respectively. As discussed in Section 1.2.4, dislocation bubbles are able to absorb vacancies from the region next to the dislocation core when their internal energy exceeds the equilibrium value. The volume of dislocation bubbles (assumed to be spherical) is calculated as

$$
V_{d}=n_{d} \omega+n_{v} \Omega
$$

where $\omega\left(\mathrm{m}^{3}\right)$ is the van der Waals' volume of a fission gas atoms. The volume of bulk bubbles (also assumed spherical) is determined as follows [3]

$$
V=n B
$$

where $B\left(\mathrm{~m}^{3}\right)$ is the volume occupied by a fission gas atom in an intra-granular bubble.

Finally, the fractional volumetric fuel gaseous swelling due to intra-granular bubbles, used in engineering fuel simulations, is calculated as

$$
\frac{\Delta V_{f}}{V_{f}}=N_{d} V_{d}+N V
$$


Table 1.1: Nomenclature and values for the parameters of the intra-granular bubble evolution model.

\begin{tabular}{|c|c|c|c|c|}
\hline Symbol & Definition & Value & U.O.M. & Reference \\
\hline$a$ & Parameter in the resolution model & $9.49 \cdot 10^{-24}$ & $\mathrm{~m}^{3}$ & {$[17$} \\
\hline$b_{1}$ & Parameter in the resolution model & $7.07 \cdot 10^{-2}$ & $\mathrm{~m}^{-1}$ & 17 \\
\hline$b_{0}$ & Parameter in the resolution model & $9.18 \cdot 10^{-23}$ & $\mathrm{~m}^{3}$ & 17 \\
\hline$c$ & Parameter in the resolution model & 7.982 & $\mathrm{~m}^{-2}$ & 17 \\
\hline$d$ & Parameter in the resolution model & $3.71 \cdot 10^{-2}$ & $m^{-2}$ & [17 \\
\hline$K$ & Parameter in the nucleation model & $1 \cdot 10^{6}$ & $\mathrm{~m}^{-1}$ & Present work \\
\hline$B$ & Volume occupied by a fission gas atom in intra-granular bubbles & $4.09 \cdot 10^{-29}$ & $\mathrm{~m}^{3}$ & $3,10,35$ \\
\hline \multirow[t]{4}{*}{$D$} & $\begin{array}{l}\text { Diffusion coefficient of fission gas atoms in } \mathrm{UO}_{2} \\
D=D_{1}+D_{2}+D_{3}\end{array}$ & & $\mathrm{~m}^{2} \mathrm{~s}^{-1}$ & 36 \\
\hline & $D_{1}=7.6 \cdot 10^{-10} \exp \left(-4.86 \cdot 10^{-19} / k T\right)$ & & & \\
\hline & $D_{2}=5.46 \cdot 10^{-25} \sqrt{\dot{F}} \exp \left(-1.91 \cdot 10^{-19} / k T\right)$ & & & \\
\hline & $D_{3}=2 \cdot 10^{-40} \dot{F}$ & & & \\
\hline$b$ & Magnitude of the $\mathrm{UO}_{2}$ Burgers vector & $3.85 \cdot 10^{-10}$ & $\mathrm{~m}$ & - \\
\hline$r_{d}$ & Dislocation core radius & $5 \cdot b$ & $\mathrm{~m}$ & E.g., 37 \\
\hline$\gamma$ & $\mathrm{UO}_{2}$ gas surface energy & 0.7 & $\mathrm{Jm}^{-2}$ & E.g., $[5$ \\
\hline$\eta$ & Number of bubbles nucleated per fission fragment & 25 & - & 5 \\
\hline$\rho_{d}$ & Average dislocation density in the fuel grain & $4 \cdot 10^{13}$ & $\mathrm{~mm}^{-3}$ & E.g., 8,38 \\
\hline$\omega$ & Van der Waals' volume of Xe & $8.5 \cdot 10^{-29}$ & $\mathrm{~m}^{3}$ & E.g., 39 \\
\hline$\Omega$ & Vacancy co-volume & $4.09 \cdot 10^{-29}$ & $\mathrm{~m}^{3}$ & 35 \\
\hline
\end{tabular}

The nominal values for the parameters of the model are summarized in Table 1.1 .

\subsection{Initial experimental validation}

As a fist step of validation of the new transient model, we present the comparison of model predictions to experimental data in terms of characteristics intra-granular bubbles in several power-ramp tested $\mathrm{UO}_{2}$ fuel samples. In particular, 'point' calculations for the local fission gas behavior in the experimental tests from White et al. [8] are performed. In the following, we present the experimental database (Section 1.4.1) and the comparisons of results to the available experimental data (Section 1.4.2). We also provide comparisons to the results obtained with the previous (normal operating conditions) bubble evolution model for the simulation of the same experiments. Finally, we compare the results to those obtained by using an empirical correlation for the resolution rate that was applied in previous models, demonstrating the importance of the multiscale coupling to MD calculations for resolution from Setyawan et al. [17] that was introduced in the present work (Section 1.4.3).

\subsubsection{Experimental database}

The experimental dataset chosen to validate the model is the SEM database by White et al. [8]. The database consists in measurements performed on $12 \mathrm{UO}_{2}$ Advanced Gas Reactor samples 
Table 1.2: Burnup, power levels and positions of SEM analyses for the experiments considered in this work for model validation [8].

\begin{tabular}{llllll}
\hline Rod ID & Burnup $\left(\mathrm{GW} \mathrm{d} \mathrm{t}^{-1}\right)$ & Ramp type & Peak power $\left(\mathrm{kW} \mathrm{m}^{-1}\right)$ & Hold time & SEM radial points \\
\hline 4000 & 20.7 & Fast & 40.0 & $30.0 \mathrm{~min}$ & 4 \\
4004 & 20.5 & Fast & 40.0 & $2.38 \mathrm{~min}$ & 4 \\
4005 & 20.8 & Fast & 40.0 & 2 min & 4 \\
4064 & 20.1 & Slow & 43.0 & - & 4 \\
4065 & 9.25 & Slow & 41.8 & - & 5 \\
4135 & 15 & Slow + Fast & 36.9 & $80 \mathrm{~s}$ & 3 \\
4136 & 12 & Slow + Fast & 39.0 & - & 5 \\
4140 & 12 & Slow & 36.0 & - & 3 \\
4162 & 12.6 & Slow & 40.0 & - & 4 \\
4163 & 12.6 & Fast & 35.0 & $2.0 \mathrm{~min}$ & 4 \\
\hline
\end{tabular}

from fuel rods irradiated up to burnups of $9-21 \mathrm{GW} \mathrm{dt}^{-1}$ in the Halden reactor. After the base irradiation, rods were subjected to power ramps or power cycling. SEM examinations were performed at various radial positions in the samples. The obtained measurements constitute a comprehensive database for the characteristics of intra-granular bubbles, and the associated local intra-granular gaseous swelling. Details about the irradiation conditions for the experiments considered in this work are given in Table 1.2

\subsubsection{Results}

The comparisons of simulations to experimental data from [8] are illustrated in Figures 1.1 and 1.2 for the intra-granular bubble radius and bubble swelling, respectively. Results refer to fission gas behavior simulations at all the SEM radial points in the experimental database (Table 1.2). The results obtained using the previous model for normal operating conditions [10] are also included.

The overall agreement between experimental data and predictions with the new transient model (red symbols in Figures 1.1 and 1.2 appears satisfactory for this initial application of the new model. In particular, sizes of tens to hundreds of nanometers for the coarsened intra-granular bubbles, and volumetric swellings of one to several percent, in these ramp-tested fuel samples are reproduced. Note that these values are orders of magnitude higher than bubbles sizes and swellings observed under normal operating conditions, and could not be captured with traditional models that do not include specific transient capabilities. This is confirmed by the comparison with the results obtained using our previous model for normal operating conditions, shown in Figures 1.1 and 1.2 In particular, as the previous model is limited to a description of nanometric intra-granular bubbles that are typical for normal operating conditions, a substantial underprediction of both bubble sizes and swellings for all considered situations is observed. Hence the engineering importance of the present development for bubble coarsening under transient conditions. Improvements in the model's physical description and parametrization, and further 


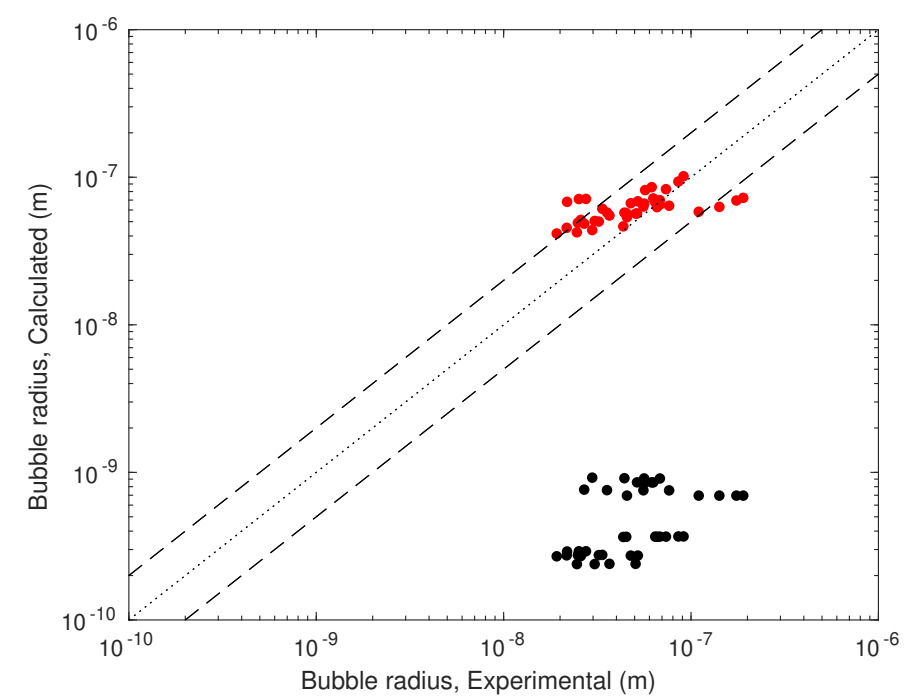

Figure 1.1: Comparisons of model predictions for bubble radius to experimental data from [8]. Each symbol corresponds to a simulation for one of the SEM radial points in the experimental database. Both results obtained with the new transient model (red symbols) and with the previous normal operation model [10] (black symbols) are included.

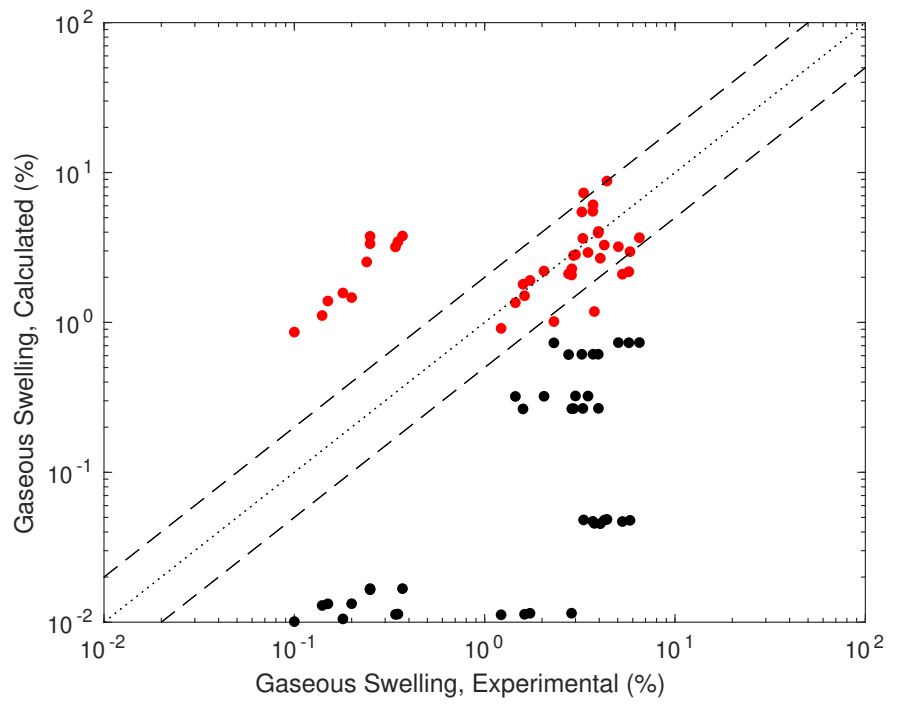

Figure 1.2: Comparisons of model predictions for bubble swelling to experimental data from [8]. Each symbol corresponds to a simulation for one of the SEM radial points in the experimental database. Both results obtained with the new transient model (red symbols) and with the previous normal operation model [10] (black symbols) are included.

application/validation to both separate-effects and integral fuel rod simulations using Bison, will be pursued in the future. 


\subsubsection{Impact of multiscale coupling for resolution}

In Figures 1.3 and 1.4, a comparisons of the predictions obtained using the resolution parameter from MD calculations from Setyawan et al. [17] (black symbols) and using the empirical resolution parameter considered in previous models [22], for the same set of simulations as in Section 1.4.2, is presented. The improvement obtained through the multiscale copuling to MD calculations from Setyawan et al. [17] for both of bubble size and swelling calculations is evident. These results further highlight the value of the multiscale approach applied at the engineering scale in this work and based on collaboration among the institutions involved in the present SciDAC project.

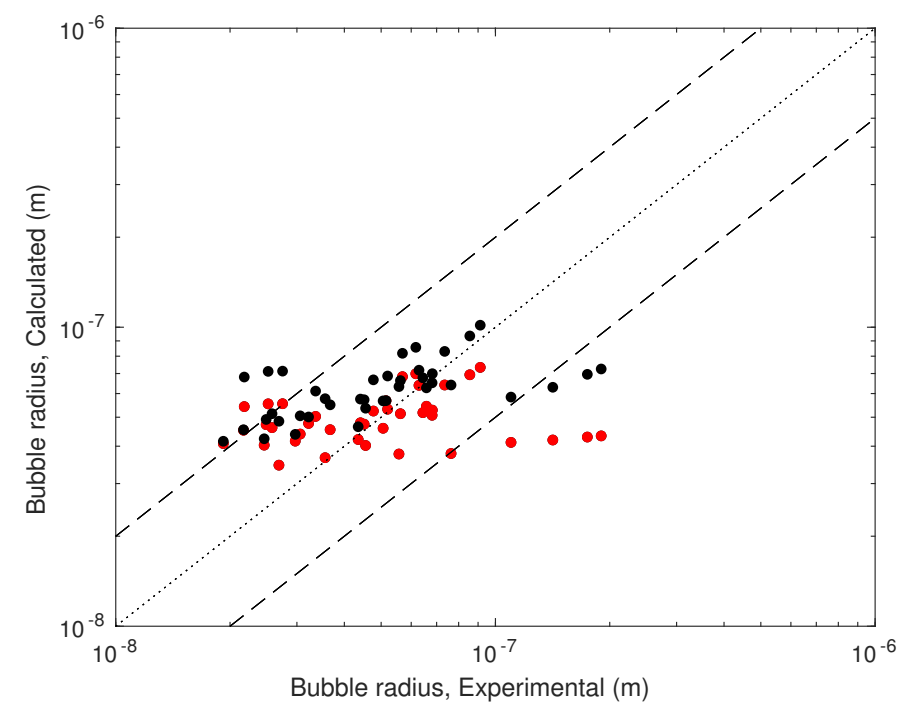

Figure 1.3: Comparisons of model predictions for bubble radius to experimental data from [8]. Each symbol corresponds to a simulation for one of the SEM radial points in the experimental database (Table 1.2). Both results obtained using the resolution model from molecular dynamics calculations from Setyawan et al. [17] (black symbols) and using the empirical resolution model [22] (red symbols) are included. 


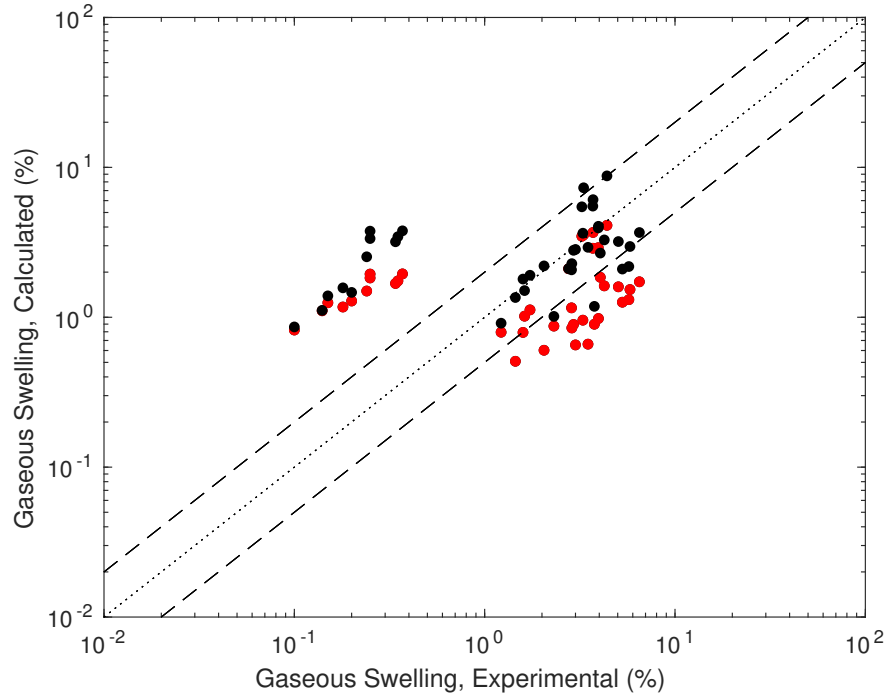

Figure 1.4: Comparisons of model predictions for bubble swelling to experimental data from [8]. Each symbol corresponds to a simulation for one of the SEM radial points in the experimental database (Table 1.2. . Both results obtained using the resolution model from molecular dynamics calculations from Setyawan et al. [17] (black symbols) and using the empirical resolution model [22] (red symbols) are included. 


\section{Application of SciDAC model to Halden fuel rod simulations using Bison}

During FY-19, the bubble evolution model for normal operating conditions in Bison developed during previous years [9] was applied to new simulations of integral fuel rod experiments. In particular, $\mathrm{Cr}_{2} \mathrm{O}_{3}$-doped $\mathrm{UO}_{2}$ fuel rod irradiations in the IFA-677.1 test performed at the Halden Reactor Project [40[41] were simulated with Bison, using the SciDAC engineering-scale bubble evolution model for normal operating conditions

In cooperation with the Consortium for Advanced Simulation of Light Water Reactors (CASL), the work also involved coupling of the SciDAC model in Bison to atomistic calculations for fission gas atom diffusivity in $\mathrm{Cr}_{2} \mathrm{O}_{3}$ doped $\mathrm{UO}_{2}$ from Los Alamos National Laboratory (LANL) [42].

In the following, we provide a brief description of the analyzed experiments (Section 2.1) and present the Bison simulation results (Section 2.2. Presented results include comparisons of calculations using the SciDAC bubble evolution model to the previous empirical models in Bison, as well as an investigation of the impact of the multiscale coupling to the LANL atomistic calculations for gas atom diffusivity.

\subsection{Description of Halden test IFA-677.1}

The Halden test IFA-677.1 [40|41|43] aimed to investigate the performance of modern fuels subjected to high initial rating. The test rig contained six rods. Two of the rods, supplied by Westinghouse, contained $\mathrm{UO}_{2}$ fuel doped with $\mathrm{Cr}_{2} \mathrm{O}_{3}$ and $\mathrm{Al}_{2} \mathrm{O}_{3}$. All rods were instrumented with pressure transducers and fuel centerline thermocouples in both ends. The test was loaded in the Halden reactor in December 2004 and completed six cycles of irradiation under HBWR (Halden Boiling Water Reactor) conditions in September 2007, achieving a rig average burnup of $\sim 26.3 \mathrm{MWd} / \mathrm{kgOX}$. Rods 1 and 5 from the IFA-677.1 test, i.e., the ones fueled with $\mathrm{Cr}_{2} \mathrm{O}_{3}$ doped $\mathrm{UO}_{2}$, have been simulated with Bison.

The main characteristics of the fuel rods in IFA-677.1 analyzed in the present work are summarized in Table 2.1.

The average linear heat rate (LHR) histories for the fuel rod test in IFA-677.1 analyzed in this work are illustrated in Figure 2.1. The Halden raw data were condensed using the Fuel Rod Analysis ToolBox developed by K. Lassmann [44]. The thermal boundary conditions at the cladding outer surface were determined using Bison's internal coolant channel model, with the 
Table 2.1: Fabrication characteristics of IFA-677.1 rods analyzed in this work [404143]

\begin{tabular}{llll}
\hline & & IFA-677.1 rod 1 & IFA-677.1 rod 5 \\
\hline Cladding material & & Zircaloy-4 & Zircaloy-4 \\
Fuel material & & $\mathrm{UO}_{2}+$ additives & $\mathrm{UO}_{2}+$ additives \\
Fill gas & $\mathrm{He}$ & $\mathrm{He}$ \\
Total active fuel stack length & $\mathrm{mm}$ & 398.6 & 403.5 \\
Drilled active section length (top) & $\mathrm{mm}$ & 109.2 & 111.0 \\
Drilled active section length (bottom) & $\mathrm{mm}$ & 109.7 & 111.1 \\
Pellet inner diameter (drilled sections) & $\mathrm{mm}$ & 1.8 & 1.8 \\
Pellet outer diameter & $\mathrm{mm}$ & 9.13 & 9.13 \\
Diametral gap & $\mu \mathrm{m}$ & 170 & 170 \\
Cladding thickness & $\mathrm{mm}$ & 0.725 & 0.725 \\
Cladding outer diameter & $\mathrm{mm}$ & 10.75 & 10.75 \\
Free volume & $\mathrm{cm}$ & 5.34 & 5.26 \\
Fill gas pressure & $\mathrm{MPa}$ & 1.35 & 1.35 \\
Fuel Cr $\mathrm{O}_{3}$ content & $\mathrm{ppm}$ & 900 & 500 \\
Fuel $\mathrm{Al}_{2} \mathrm{O}_{3}$ content & $\mathrm{ppm}$ & 200 & 200 \\
Fuel $\mathrm{U}_{2} 235$ enrichment & $\%$ & 4.94 & 4.91 \\
Initial fuel density & $\mathrm{kg} / \mathrm{m}^{3}$ & 10690 & 10700 \\
Fuel average grain radius & $\mu \mathrm{m}$ & 28 & 22.5 \\
\hline
\end{tabular}

coolant inlet temperature history determined from the Halden raw data. The Jens-Lottes heat transfer correlation, which is recommended for Halden HBWR conditions was applied.

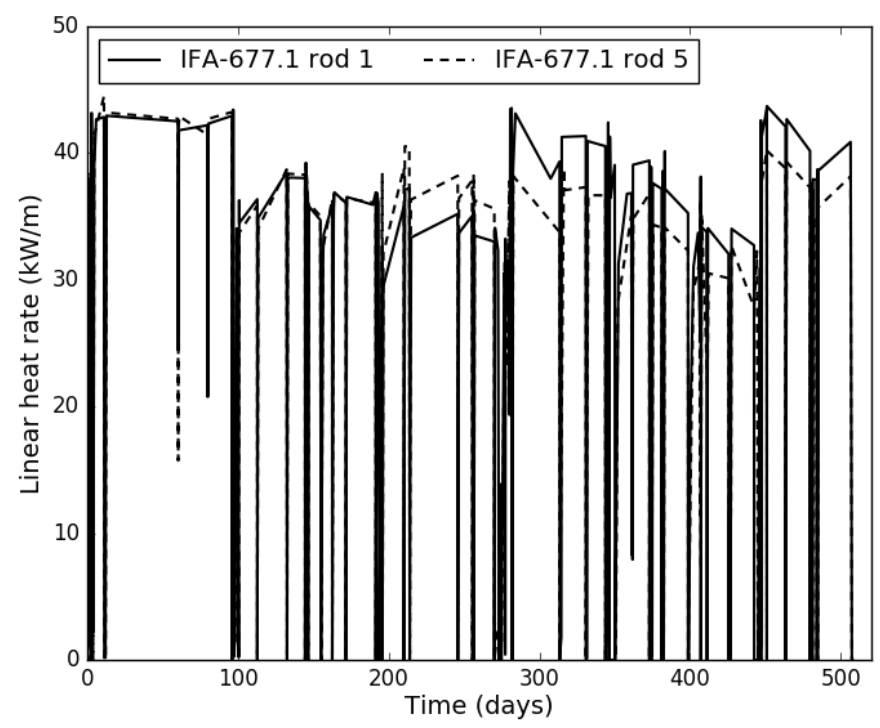

Figure 2.1: Average linear heat rate histories for IFA-677.1 rods 1 and 5 


\subsection{Bison simulation results}

Figures 2.2 and 2.3 show the comparisons of Bison integral FGR predictions to the experimental data from Halden [40] for IFA-677.1 rods 1 and 5, resepctively. Results are presented for simulations using the original Bison intra-granular fission gas model, which is based on epirical fits from [5] (gray lines), the new SciDAC fission gas model (black lines) and the new SciDAC model with the additional multiscale coupling to the atomistic calculations for fission gas atom diffusivity in $\mathrm{Cr}_{2} \mathrm{O}_{3}$ doped $\mathrm{UO}_{2}$ from LANL [42] (blue lines).

Results demonstrate the improvement associated with the introduction of the SciDAC engineering fission gas model in Bison, as well as the further improvement obtained with the multiscale coupling to the atomistic model for diffusivity. Predictions obtained with the combined developments are indeed very satisfactory, considering the inherent uncertainties in fission gas release predictions in engineering fuel rod calculations.

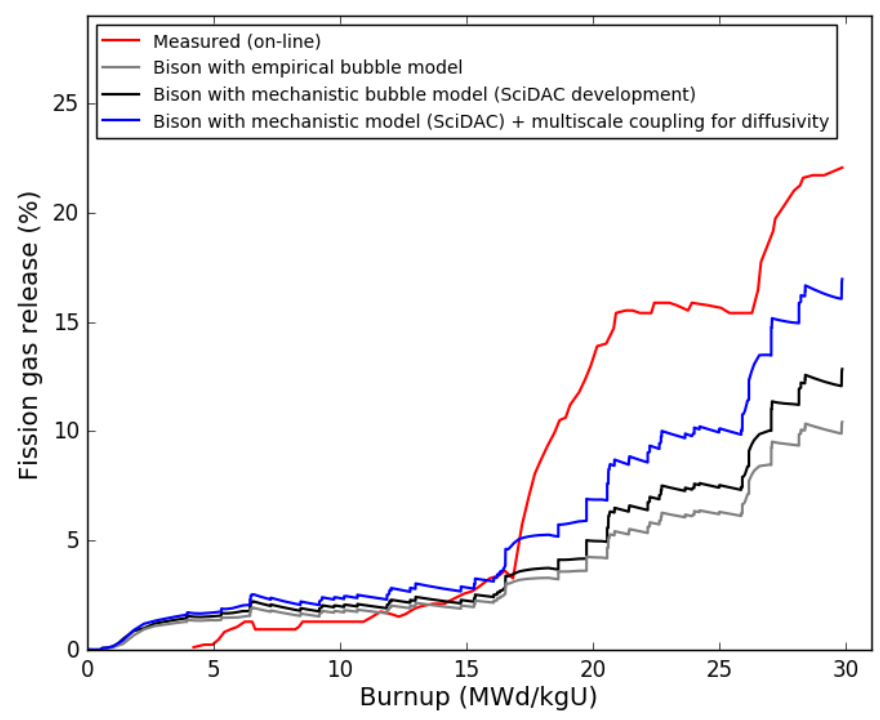

Figure 2.2: Comparisons of Bison calculations to measured fission gas release for the Halden test IFA$677.1 \operatorname{rod} 1$ 


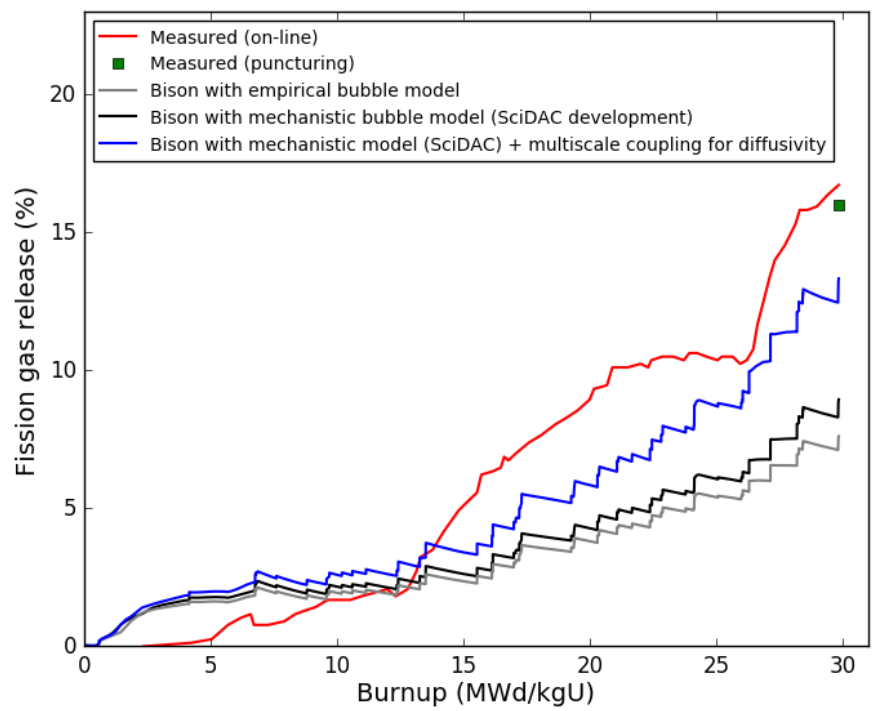

Figure 2.3: Comparisons of Bison calculations to measured fission gas release for the Halden test IFA$677.1 \operatorname{rod} 5$ 


\section{Conclusions}

This report described completion of the INL SciDAC milestone M3MS-19IN0101201 on Modeling Intra-granular Fission Gas Bubble Evolution in Uranium Dioxide during Transients. The work performed encompassed the development, testing and implementation in the Bison code of an engineering model for intra-granular fission gas bubble evolution that is applicable to both normal operating and transient LWR conditions, and utilizes a multiscale approach. Specific contributions that were obtained through the present work are:

- The development and initial validation of a new model for intra-granular bubble evolution at the engineering scale that extends the previously developed single-size cluster dynamics model to include complexities related to transient behavior, in particular, bubble coarsening and the associated transient fuel swelling.

- The coupling of the engineering bubble evolution model to molecular dynamics calculations for the gas atom resolution rate performed in this project [17], which demonstrated an operational multiscale approach successfully applied at the engineering scale and based on collaboration among the institutions involved.

- The application of the previously developed bubble evolution model in Bison to engineering fuel rod simulations of Halden experiments, which further demonstrated the engineering application of the SciDAC developments, as well as the improvements in fission gas release predictions compared to the empirical models previously used in Bison.

A relatively simple but physics-based modeling approach at the engineering scale was applied in order to comply with the computational requirements associated with the application in engineering codes. On the other hand, thanks to its physical basis, the model can be informed with improved parameters derived at the lower length scales, thus providing an ideal framework for multiscale modeling applied in engineering calculations. While such a multiscale coupling was already demonstrated in this work with the usage of resolution parameters from MD calculations and diffusion coefficients from DFT calculations, further improvements in this respect and additional validation of the developed multiscale modeling capabilites will be pursued in future work. Furthermore, comparisons of the engineering-scale bubble evolution models to advanced cluster dynamics models developed in the present SciDAC project (Xolotl code) are planned. These comparisons are expected to provide further insight into the impact of the assumptions applied and potential improvements in the parametrization of the engineering-scale models. 


\section{Acknowledgments}

Dr. Lelio Luzzi, Mr. Tommaso Barani, Mr. A. Magni and Dr. Davide Pizzocri at Politecnico di Milano, Department of Energy, Nuclear Engineering Division (Milan, Italy) are acknowledged for their substantial contributions to this work.

This work was funded by the U.S. Department of Energy Scientific Discovery through Advanced Computing (SciDAC) project on Simulation of Fission Gas in Uranium Oxide Nuclear Fuel.

The submitted manuscript has been authored by a contractor of the U.S. Government under Contract DE-AC07-05ID14517. Accordingly, the U.S. Government retains a non-exclusive, royalty free license to publish or reproduce the published form of this contribution, or allow others to do so, for U.S. Government purposes. 


\section{References}

[1] D. R. Olander. Fundamental Aspects of Nuclear Reactor Fuel Elements. Technical Information Center - Energy Research and Development Administration, University of California, Berkeley, CA, USA, 1976.

[2] $\mathrm{Hj}$. Matzke. Gas release mechanisms in $\mathrm{UO}_{2}$ - A critical review. Radiation effects, 53:219$242,1980$.

[3] D. R. Olander and D. Wongsawaeng. Re-solution of fission gas - A review: Part I. Intragranular bubbles. Journal of Nuclear Materials, 354(1-3):94-109, 2006.

[4] M.V. Speight. A Calculation on the Migration of Fission Gas in Material Exhibiting Precipitation and Re-solution of Gas Atoms Under Irradiation. Nuclear Science and Engineering, 37:180-185, 1969.

[5] R. J. White and M. O. Tucker. A new fission-gas release model. Journal of Nuclear Materials, 118(1):1-38, 1983.

[6] M. Mogensen, C.T. Walker, I.L.F. Ray, and M. Coquerelle. Local fission gas release and swelling in water reactor fuel during slow power transients. Journal of Nuclear Materials, 131:162-171, 1985.

[7] S. Kashibe, K. Une, and K. Nogita. Formation and growth of intragranular fission gas bubbles in $\mathrm{UO}_{2}$ fuels with burnup of 6-83 GWd/t. Journal of Nuclear Materials, 206:2234, 1993.

[8] R. J. White, R. C. Corcoran, and P. J. Barnes. A Summary of Swelling Data Obtained from the AGR/Halden Ramp Test Programme. Technical Report R\&T/NG/EXT/REP/0206/02, 2006.

[9] G. Pastore. M3MS-18IN0101092: Develop and implement in the BISON code a new engineering model for intra-granular fission gas behavior in uranium dioxide. Technical Report INL/EXT-18-51614, Idaho National Laboratory, September 2018.

[10] D Pizzocri, G Pastore, T Barani, A Magni, L Luzzi, P Van Uffelen, S A Pitts, A Alfonsi, and J D Hales. A model describing intra-granular fission gas behaviour in oxide fuel for advanced engineering tools. Journal of Nuclear Materials, 502:323-330, 2018.

[11] G. Pastore, D. Pizzocri, C. Rabiti, T. Barani, P. Van Uffelen, and L. Luzzi. An effective numerical algorithm for intra-granular fission gas release during non-equilibrium trapping and resolution. Journal of Nuclear Materials, 509:687-699, 2018. 
[12] G. Pastore, T. Barani, D. Pizzocri, A. Magni, and L. Luzzi. Modeling fission gas release and bubble evolution in $\mathrm{UO}_{2}$ for engineering fuel rod analysis. In Proc. of Top Fuel 2018, Prague, Czech Republic, September 30 - October 4, 2018.

[13] R. J. White. The growth of intra-granular bubbles in post-irradiation annealed $\mathrm{UO}_{2}$ fuel. In Technical committee meeting on nuclear fuel behaviour modelling at high burnup and its experimental support, pages 91-104, Windermere, UK, 2000. IAEA.

[14] Pekka Losonen. On the behaviour of intragranular fission gas in $\mathrm{UO}_{2}$ fuel. Journal of Nuclear Materials, 280(1):56-72, 2000.

[15] P. Garcia, G. Martin, C. Sabathier, G. Carlot, A. Michel, P. Martin, B. Dorado, M. Freyss, M. Bertolus, R. Skorek, J. Noirot, L. Noirot, O. Kaitasov, and S. Maillard. Nucleation and growth of intragranular defect and insoluble atom clusters in nuclear oxide fuels. $\mathrm{Nu}$ clear Instruments and Methods in Physics Research, Section B: Beam Interactions with Materials and Atoms, 277:98-108, 2012.

[16] Pekka Losonen. On the effect of irradiation-induced resolution in modelling fission gas release in $\mathrm{UO}_{2}$ LWR fuel. Journal of Nuclear Materials, 496:140-156, 2017.

[17] Wahyu Setyawan, Michael W.D. Cooper, Kenneth J. Roche, Richard J. Kurtz, Blas P. Uberuaga, David A. Andersson, and Brian D. Wirth. Atomistic model of xenon gas bubble re-solution rate due to thermal spike in uranium oxide. Journal of Applied Physics, 124(7), 2018.

[18] M. S. Veshchunov and V. I. Tarasov. Modelling of irradiated $\mathrm{UO}_{2}$ fuel behaviour under transient conditions. Journal of Nuclear Materials, 437(1-3):250-260, 2013.

[19] C. Baker. The fission gas bubble distribution in uranium dioxide from high temperature irradiated SGHWR fuel pins. Journal of Nuclear Materials, 66:283-291, 1977.

[20] M. S. Veshchunov. On the theory of fission gas bubble evolution in irradiated $\mathrm{UO}_{2}$ fuel. Journal of Nuclear Materials, 277:67 - 81, 2000.

[21] J. Spino, J. Rest, W. Goll, and C. T. Walker. Matrix swelling rate and cavity volume balance of $\mathrm{UO}_{2}$ fuels at high burn-up. Journal of Nuclear Materials, 346(2-3):131-144, 2005.

[22] J. A. Turnbull. The distribution of intragranular fission gas bubbles in $\mathrm{UO}_{2}$ during irradiation. Journal of Nuclear Materials, 38(2):203-212, 1971.

[23] G. Martin, P. Garcia, C. Sabathier, L. Van Brutzel, B. Dorado, F. Garrido, and S. Maillard. Irradiation-induced heterogeneous nucleation in uranium dioxide. Physics Letters, Section A: General, Atomic and Solid State Physics, 374(30):3038-3041, 2010.

[24] K. Govers, C. L. Bishop, D. C. Parfitt, S. E. Lemehov, M. Verwerft, and R. W. Grimes. Molecular dynamics study of Xe bubble re-solution in $\mathrm{UO}_{2}$. Journal of Nuclear Materials, 420(1-3):282-290, 2012. 
[25] J. Rest and A. Zawadski. FASTGRASS : A Mechanistic Model for the Prediction of Xe, I, $\mathrm{Cs}, \mathrm{Te}, \mathrm{Ba}$, and Sr Release from Nuclear Fuel under Normal and Severe-Accident Conditions. Report NUREG/CR-5840, 1993.

[26] Frank Ham. Theory of diffusion-limited precipitation. J. Phys. Chem. Solids, 6:335-351, 1958.

[27] Samuel T. Murphy, Eleanor E. Jay, and Robin W. Grimes. Pipe diffusion at dislocations in $\mathrm{UO}_{2}$. Journal of Nuclear Materials, 447(1-3):143-149, 2014.

[28] M.V. Speight and W. Beere. Vacancy potential and void growth on grain boundaries. Metal Science, 9:190-191, 1975.

[29] Donald R. Olander. Interaction of stresses with inclusions in solids - a review. Journal of Nuclear Materials, 92:163-183, 1980.

[30] T. Barani, G. Pastore, D. Pizzocri, D. A. Andersson, C. Matthews, A. Alfonsi, K. A. Gamble, P. Van Uffelen, L. Luzzi, and J. D. Hales. Multiscale modeling of fission gas behavior in $\mathrm{U}_{3} \mathrm{Si}_{2}$ under LWR conditions. Journal of Nuclear Materials, 522:97-110, aug 2019.

[31] David A. Andersson, Michael R. Tonks, Luis Casillas, Shyam Vyas, Pankaj Nerikar, Blas P. Uberuaga, and Christopher R. Stanek. Multiscale simulation of xenon diffusion and grain boundary segregation in $\mathrm{UO}_{2}$. Journal of Nuclear Materials, 462:15-25, 2015.

[32] Samuel T. Murphy, Paul Fossati, and Robin W. Grimes. Xe diffusion and bubble nucleation around edge dislocations in $\mathrm{UO}_{2}$. Journal of Nuclear Materials, 466:634-637, 2015.

[33] L. K. Mansur. Void swelling in metals and alloys under irradiation: An assessment of the theory. Nuclear Technology, 40(1):5-34, 1978.

[34] S. Torquato. Random Heterogeneous Materials: Microstructure and Macroscopic Properties, volume 82. 2013.

[35] Toshiaki Kogai. Modelling of fission gas release and gaseous swelling of light water reactor fuels. Journal of Nuclear Materials, 244:131-140, 1997.

[36] J. A. Turnbull, R. J. White, and C. Wise. The diffusion coefficient for fission gas atoms in uranium dioxide. In International Working Group on Water Reactor Fuel Performance and Technology, Technical committee on water reactor fuel element computer modelling in steady state, transient and accident conditions, Preston, U.K., 1989.

[37] M. S. Veshchunov and V. E. Shestak. Modelling of fission gas release from irradiated $\mathrm{UO}_{2}$ fuel under high-temperature annealing conditions. Journal of Nuclear Materials, 430(13):82-89, 2012.

[38] Riley J. Parrish, Xiang Liu, Alexander Winston, Jason M. Harp, and Assel Aitkaliyeva. Radial microstructural evolution in low burnup fast reactor MOX fuel. Journal of Nuclear Materials, 523:182 - 188, 2019. 
[39] Giovanni Pastore, Lelio Luzzi, Valentino Di Marcello, and Paul Van Uffelen. Physicsbased modelling of fission gas swelling and release in $\mathrm{UO}_{2}$ applied to integral fuel rod analysis. Nuclear Engineering and Design, 256:75-86, 2013.

[40] R. Jošek. The High Initial Rating Test IFA-677: Final Report on In-Pile Results. Technical Report HWR-872, OECD Halden Reactor Project, April 2008.

[41] H. K. Jenssen. PIE Report on $\mathrm{Six}_{\mathrm{UO}_{2}}$ Fuel Rods Irradiated in IFA-677 High Initial Rating Test. Technical Report HWR-968, OECD Halden Reactor Project, March 2010.

[42] M.W.D. Cooper, C.R. Stanek, and D.A. Andersson. The Role of Dopant Charge State on Defect Chemistry and Grain Growth of Doped $\mathrm{UO}_{2}$. In: TMS 2019, San Antonio, USA, March 10-14, 2019.

[43] B. Thérache. The High Initial Rating Test, IFA-677.1: Results after First Cycle of Irradiation. Technical Report HWR-819, OECD Halden Reactor Project, September 2005.

[44] K. Lassmann, A. Schubert, J. van de Laar, and P. Van Uffelen. The 'Fuel Rod Analysis ToolBox': a general program for preparing the input of a fuel rod performance code. Annals of Nuclear Energy, 81:332-335, 2015. 